\title{
SEED PROPAGATION AND RE-INTRODUCTION OF THE U.S. FEDERALLY ENDANGERED HAWAIIAN ENDEMIC, PLATANTHERA HOLOCHILA (HBD.) KRZL. (ORCHIDACEAE)
}

\author{
LAWRENCE W. ZETTLER ${ }^{1, *}$, ERIN M. WOOD ${ }^{1,2}$, LYNNAUN \\ J. A. N. JOHNSON ${ }^{1,3}$, ANNA K. KIRK ${ }^{1,4}$, and STEVEN P. PERLMAN ${ }^{5}$ \\ ${ }^{1}$ Department of Biology, Illinois College, 1101 West College Avenue, Jacksonville, IL 62650 USA \\ ${ }^{2}$ Current address: Department of Plant Pathology, Fifield Hall, University of Florida, Gainesville, FL 32611 USA \\ ${ }^{3}$ Current address: Department of Biology, Western Illinois University, 1 University Circle, Macomb, IL 61455 USA \\ ${ }^{4}$ Current address: Department of Entomology, 243 Natural Sciences Building, Michigan State University, East Lansing, MI 48824 USA \\ ${ }^{5}$ National Tropical Botanical Garden, 3530 Papalina Road, Kalaheo, HI 96741 USA \\ *Corresponding author: lwzettle@mail.ic.edu; Tel.: (217) 245-3479; Fax: (217) 245-3358
}

\section{ABSTRACT}

Platanthera holochila $(\mathrm{Hbd}$.) Krzl. [syn = Peristylus holochila $(\mathrm{Hbd}) \mathrm{N}$. Hallé] is the rarest of three orchids endemic to the Hawaiian Archipelago. As of 2011, 33 individual plants of this U.S. Federally endangered species remained on three islands with only one specimen known to occur on Kauai. This paper presents a summary of experiments aimed at cultivating this species from seed leading to the reintroduction of seedlings. We describe: 1) the mycorrhizal fungi acquired from $P$. holochila protocorms on Molokai, 2) the role of light vs. dark pretreatment on symbiotic seed germination using a mycorrhizal fungus from Florida, and 3) asymbiotic germination on three media (Murashige and Skoog, Knudson C, P723). Protocorms recovered in situ using seed packets yielded seven strains of a mycorrhizal fungus assignable to the anamorphic genus Epulorhiza Moore, but none of these strains prompted seed germination in vitro. Using the mycorrhizal fungus from Florida, no significant differences were detected between light pre-treatment vs. dark incubation on seed germination or development, but statistical differences were evident among two agar types tested. Seeds sown on acidified (pH 5.0) asymbiotic medium P723 (PhytoTechnology Labs) developed to the leaf-bearing stage 351 days after sowing and incubation in darkness at $16-19^{\circ} \mathrm{C}$. Seedlings illuminated 451 days after sowing were eventually established on soil in a greenhouse (ex vitro). A total of 85 seedlings were promptly transported to Hawaii in March 2011. A minimum of 3.1 years is required for the propagation of $P$. holochila from seed using acidified asymbiotic medium P723.

Key words: conservation, germination, mycorrhizal fungi, terrestrial, seedlings, Kauai

\section{Introduction}

Known for its multitude of endemic species, the remote Hawaiian Archipelago has been referred to as the "Endangered Species Capital of the World" (Sugii 2011). Of its 1,159 native plant species, $9 \%$ are now extinct and ca. $53 \%$ are at risk of extinction (Sakai et al. 2002). In 2009 , more than one third (40.6\%) of all U.S. Federallylisted plants were native to Hawaii (U.S. Fish and Wildlife Service 2009, cited in Sugii 2011), and 85 additional taxa may be added to the endangered species list in the next five years (Yoshioka 2009, cited in Sugii 2011). To conserve the rarest species in peril, various ex situ and in vitro methods are now viewed as necessary to augment the active management of wild plant populations (Saransan et al. 2006), with emphasis on propagation of seed-derived tissue to maintain genetic diversity (Sugii 2011). Among the angiosperms, terrestrial orchids are notorious for having fastidious seed germination requirements complicated by their absolute natural requirement for mycorrhizal fungi. Thus, efforts to conserve these highly vulnerable plants must take into account the preservation (storage) of compatible mycorrhizal strains in addition to seed (Rasmussen 1995).

Platanthera holochila $(\mathrm{Hbd}$.) Krzl. [syn = Peristylus holochila (Hbd) N. Hallé], the subject of this study (Fig. 1a), is the rarest of three orchids endemic to the Hawaiian
Archipelago. This species is found in high altitude (1000$2000 \mathrm{~m}$ ) cloud forest bogs on raised hummocks that are rich in organic matter and high in acidity (Fig. 1b, 1c). As of 2011, 33 individual plants of this U.S. Federally endangered species remained on three islands (Fig. 1d) with only one specimen known to occur on Kauai. In 1977, a coordinated effort to propagate this terrestrial orchid from seed was initiated involving specialists (e.g., University of Hawaii, Lyon Arboretum) and commercial growers alike. Despite vigorous attempts spanning a 25 year period, however, the propagation of $P$. holochila remained elusive (e.g., Walker 1994). During this time, the decline of $P$. holochila in situ was evident, exacerbated by threats imposed by invasive species (e.g., wild pigs) and a natural disaster (Hurricane Iniki on Kauai, 1992), raising the distinct possibility that $P$. holochila would succumb to extinction.

In a collaborative project between Illinois College and the National Tropical Botanical Garden initiated in 2002, the technique of in vitro symbiotic seed germination was applied to $P$. holochila for the first time. The mycorrhizal fungus utilized for this purpose, Epulorhiza repens (N. Bernard) R. T. Moore, originated from the roots of a terrestrial orchid from Florida (Stewart et al. 2003). This fungus was chosen because of its reliable track record for facilitating seed germination among a wide range of orchid taxa in North America (Zettler 2008), and because 

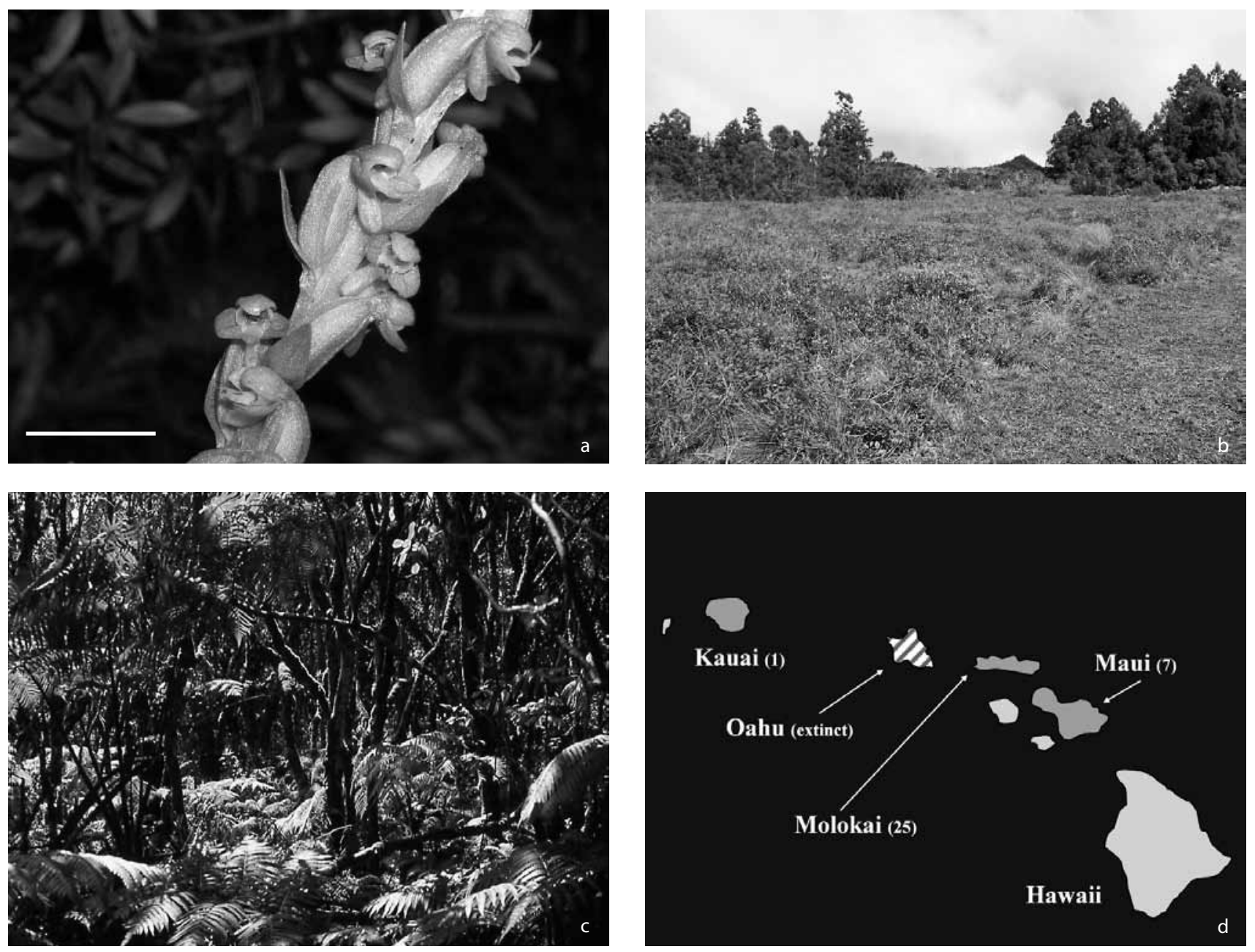

Fig. 1 Platanthera holochila, its habitat, and its distribution throughout the Hawaiian Archipelago. (a) A cluster of eight flowers on a portion of the inflorescence from the solitary specimen on Kauai. Scale bar $=1.5 \mathrm{~cm}$. (b) High elevation bog (Alakali Swamp) on Kauai where the only known P. holochila specimen is thought to occur on that island. (c) Shaded bog at Kamakou Preserve on Molokai known to harbor ca. 25 individual specimens. (d) Distribution of $P$. holochila in Hawaii. The number of known plants thought to occur as of 2011 is listed for each island in parentheses.

mycorrhizal strains from Hawaii were unavailable at the time. Preliminary results suggested that this fungus had practical merit for the immediate recovery of $P$. holochila, but because this fungus originated from Florida - not Hawaii - concerns were raised that the deliberate release of mycotrophic seedlings would result in the release of this exotic fungus into ecologically sensitive areas (Zettler et al. 2005a). This paper presents a summary of the various experiments that ensued leading to the reintroduction of P. holochila seedlings on the islands of Kauai and Molokai in March 2011. Among the experiments described herein are: 1) attempts to recover mycorrhizal fungi from P. holochila protocorms and roots of mature plants from Molokai, 2) the role of light pre-treatment versus dark incubation on symbiotic seed germination, and 3) the use of carbon-based media (Murashige and Skoog, Knudson C, P723) to facilitate seed germination and development in vitro without fungi (asymbiotic germination). In addition, we provide the details of the best available protocol used in the artificial seed propagation of $P$. holochila leading to its reintroduction on Molokai and Kauai.

\section{Materials and Methods}

\section{Fungal isolation and seed germination in situ}

Several attempts to recover mycorrhizal fungi from $P$. holochila were carried out involving roots of mature plants, and protocorms acquired in situ. Segments of lateral roots (ca. 1-5 cm in length) from one mature plant on Maui and two from Molokai were obtained on 6 March 2002, and 23 August 2002, respectively. An additional root segment from Molokai was collected on 27 July 2004. Segments were placed in plastic bags, sealed, and promptly flown to the mainland, arriving within 4-7 days. Immediately upon arrival, root segments were rinsed in tap water to remove surface debris, then surface sterilized for $1 \mathrm{~min}$. using a solution of $5 \%$ absolute ethanol (EtOH), 5\% Clorox ${ }^{\circ}$ bleach $(5.25 \% \mathrm{NaOCl}$; Clorox Co., Oakland, CA, USA), and 90\% sterile DI water. The solution was then decanted off, and tissues were rinsed twice in sterile DI water. Peloton extraction and fungal isolation via hyphal tips followed the general procedure 
described by Currah et al. $(1987,1990)$. Using a sterile scalpel under a laminar flow hood, the epidermal layer of each root piece was gently scraped away and discarded. The exposed cortical region was then macerated using a scalpel and forceps, and clumps of cells were transferred to a drop of sterile DI water within a $9 \mathrm{~cm}$ diam. Petri plate. This procedure resulted in the release of individual cortical cells into the water droplet which were visible to the naked eye. Molten modified Melin-Norkran's agar (MMN; Marx 1969) was poured over the droplet, gently swirled to disperse the cortical cells throughout the agar, and allowed to solidify at ambient temperature. Plates were incubated up to 10 days at ambient temperature. Assisted by a dissection microscope, plates were inspected daily for signs of active fungal growth emanating from cortical cells/pelotons suspended in the agar. A portion of one mature root (Molokai specimen) was withheld from fungal isolations to determine the extent of peloton colonization and digestion.

To document seed germination in situ and to recover the mycorrhizal fungi that likely triggered this process, the seed baiting technique described by Rasmussen and Whigham (1993) was adopted during two separate attempts on Molokai. This involved placing ca. 50-500 seeds between two sheets of nylon mesh plankton netting (95 $\mu \mathrm{m}$ pore size, \#65-2222M Carolina Biological Supply Co., Burlington, NC, USA) suspended within $35 \mathrm{~mm}$ photographic slide mounts (Polaroid Corp., MA,
USA). Each packet contained a separate seed source, and packets were attached to one another $(10 \mathrm{~cm}$ apart $)$ using aluminum wire. Each line was buried at a depth in soil comparable to the depth observed for mature roots of existing plants (ca. $10-20 \mathrm{~cm}$ ). The line was then attached to nearby vegetation, and marked with flagging tape to permit relocation and retrieval. Seeds from three different collections were utilized for this purpose: S120, S125 (\#6), S130 (Table 1). A total of 18 packets along 4 lines were buried on Molokai on 9 August 2003 involving S120 and S125 (\#6) seed (9 packets/2 lines per seed source). The second sowing took place nearly one year later (27 July 2004) involving S130 (9 packets/3 lines, 3 per line) and S125 seed (12 packets/4 lines, 3 per line). On this same day, all packets from the previous year's sowing were retrieved, sealed in plastic bags (one line per bag), and transported to a laboratory at the University of Hawaii at Manoa on 30 July 2004. Upon arrival, each packet was gently opened and inspected for protocorms with a dissection microscope. Protocorm development was assessed using growth stage values reported for in vitro studies of Platanthera (e.g., Zettler et al. 2005a), where Stage $0=$ no germination, Stage $1=$ rhizoids evident, Stage 2 = rupture of testa by enlarged embryo, Stage 3 = appearance of shoot region, Stage $4=$ emergence of leaf from shoot, and Stage $5=$ leaf elongation. Protocorms from two of the three packets were then surface sterilized, rinsed, and plated on MMN using the

Table 1 Seed sources utilized for experiments involving in situ seed baiting, and in vitro germination of Platanthera holochila. All seeds were acquired from ripe (yellowing) mature capsules derived from natural pollination. Seeds were stored over $\mathrm{CaSO}_{4}$ desiccant (Drierite, W.A. Hammond Co., Xenia, $\mathrm{OH}, \mathrm{USA}$ ) within 10 days of collection, and stored at $-7^{\circ} \mathrm{C}$ in darkness until use. ( ${ }^{*}$ The original source of S140 is questionable due to error in record-keeping.)

\begin{tabular}{|l|l|l|l|}
\hline Seed Source & Population & Date Collected & Notes \\
\hline S120 & Molokai & 23 September 2002 & Seed mixture, 12 capsules from 4 separate plants \\
\hline S125(\#2) & Molokai & 7 November 2002 & Seed mixture, 15 capsules from 6 separate plants \\
\hline S125 \#6) & Molokai & 7 November 2002 & Seed mixture, 46 capsules from 3 separate plants \\
\hline S129 & Kauai & 5 September 2003 & Seed mixture from 10 capsules, solitary plant \\
\hline S130 & Molokai & 7 November 2002 & $\begin{array}{l}\text { Leftover S125(\#6) seed used in previous experiment and re-frozen } \\
\text { instead of discarded (after desiccation) }\end{array}$ \\
\hline S133 & Kauai & 9 September 2004 & Seed mixture, 9 capsules from 4 inflorescences on solitary plant (clump) \\
\hline S134 & Kauai & 7 October 2004 & Seed mixture, 3 capsules, solitary plant \\
\hline S139 & Molokai & 10 November 2004 & Seed mixture, 1-2 capsules from Plant \#6 \\
\hline S140* & Kauai & 22 September 2005 & Seed mixture, 9 capsules, solitary plant \\
\hline S142 & Kauai & 22 September 2005 & Seed mixture, 16 capsules, solitary plant \\
\hline S143 & Kauai & 22 September 2005 & Seed mixture, 22 capsules, solitary plant \\
\hline S145 & Molokai & 25 October 2005 & Seed mixture from 10 capsules \\
\hline S146 & Kauai & 14 September 2006 & \\
\hline S153 & Molokai & 29 November 2006 & Seed mixture from 18-20 capsules, Plant \#20 \\
\hline S154 & Molokai & 29 November 2006 & Seed mixture from 27 capsules, Plant \#20 \\
\hline S155 & Molokai & 29 November 2006 & Seed mixture from 10 capsules, Plant \#19 \\
\hline S156 & Molokai & 29 November 2006 & Seed mixture from 8 capsules, Plant \#23 \\
\hline S157 & Molokai & 29 November 2006 & Seed mixture from 13 capsules, Plant \#21 \\
\hline S158 & Molokai & 29 November 2006 & Seed mixture from 15 capsules, Plant \#24 \\
\hline
\end{tabular}

European Journal of Environmental Sciences, Vol. 1, №. 2 
technique described by Zettler et al. (2005b). A third packet containing 7 protocorms was retained for fungal isolations that resumed at Illinois College one week later (4 August 2004). Each of the 7 protocorms were divided in half longitudinally using a sterile scalpel, with one half plated on MMN agar, and the other half over malt extract agar (Difco Laboratories, Detroit, MI, USA). The $\mathrm{pH}$ of each agar type was lowered to 5.0 prior to autoclaving to parallel the acidity of the soils reported at the Molokai site ( $\mathrm{pH}$ 4.3; Zettler et al. 2005a). After surface sterilization, protocorms were macerated in a droplet of water, and immersed under molten agar using the procedure outlined by Zettler et al. (2005b). Plates were incubated up to 10 days at ambient temperature. During this time, fungal hyphae observed emerging from pelotons were sub-cultured onto potato dextrose agar (PDA; Difco Laboratories, Detroit, MI, USA) using a sterile scalpel and the aid of a dissection microscope. After one month on PDA, cultures were visually compared. Those with subtle differences in colony color, growth rate, and margin texture were assigned an individual accession number. Cultures were stored in refrigeration $\left(4-6{ }^{\circ} \mathrm{C}\right)$ over PDA slants in screw-capped tubes and sub-cultured every 6-12 months. Each isolate was also deposited into two international culture collections (CBS, The Netherlands; UAMH, Alberta, Canada) for safekeeping and future use via cryopreservation. Growth rates of cultures maintained at Illinois College were calculated using the technique described by Currah et al. (1990) on corn meal agar (CMA; Difco Laboratories, Detroit, MI, USA) and PDA adjusted to two $\mathrm{pH}$ ranges $(5.0,7.0)$. Hyphae from aerial and submerged mycelia were inspected by light microscopy for the presence of monilioid cells on aged ( $>1$ month old) cultures.

\section{Symbiotic seed germination}

Two separate experiments were carried out involving the inoculation of seed with mycorrhizal fungi in vitro (symbiotic seed germination). The first experiment utilized the mycorrhizal fungus from Florida (Epulorhiza repens, UAMH 9824) reported previously (Zettler et al. 2005a) to determine if light-pretreatment and/or the addition of soil had a stimulatory effect on germination and development compared to standard protocols (e.g., Clements et al. 1986; Dixon 1987; Smreciu and Currah 1989). Four seed sources were used for this experiment: S120, S125(\#2), S125(\#6), S129 (Table 1), and two seed sources were paired in each Petri plate (Combination A $=$ S120 paired with S129; Combination B = both S125 sources paired). A total of 96 plates were prepared (48 Combination A, 48 Combination B). Seeds in half (24 of 48 ) of the plates in each combination received light pretreatment whereas the other half remained in darkness. Half of the 24 plates in each combination contained modified oats medium (MOM; Clements et al. 1986) whereas the other half contained a standard oat meal agar (OMA, 2.5 g rolled oats, 7.0 g agar, 11 DI water; Dixon 1987) amended with soil collected from the Molokai population on 9 August 2003. Thus, treatments for the 48 Combination A plates consisted of: 12 plates OMA-soil + light pre-treatment, 12 plates OMA-soil + darkness, 12 plates $\mathrm{MOM}+$ light pre-treatment, 12 plates $\mathrm{MOM}+$ darkness. Two of the 12 plates in each treatment were not inoculated with the mycorrhizal fungus and served as controls. The 48 Combination B plates received the same treatment set-up. Soil collected from Molokai consisted of a grab sample (mixture of at least 5 separate equal samples) acquired adjacent to existing plants. The soil was placed in plastic bags, sealed, and promptly transported to Illinois College within 10 days. Upon arrival, soil was immediately frozen $\left(-7^{\circ} \mathrm{C}\right)$ until use. Soil was then allowed to thaw at ambient temperature, placed into a beaker, sealed with aluminum foil, and autoclaved $\left(15 \mathrm{~min}\right.$ at $\left.121^{\circ} \mathrm{C}, 19 \mathrm{psi}\right)$. After autoclaving, soil remained in the covered beaker for ca. 24 hours and was re-autoclaved a second time prior to its addition to OMA. The Petri plate apparatus consisted of a lower glass portion $\left(\mathrm{Pyrex}^{\circ}, 80 \times 40\right.$, No. 3140 , Germany) coupled to an upper lid from the lower portion of a sterile $9 \mathrm{~cm}$ diam. plastic Petri dish. Each lower dish accommodated $40 \mathrm{ml}$ of agar, and each OMA plate contained $3 \mathrm{~g}$ soil. Prior to autoclaving, both OMA-soil and MOM were acidified to $\mathrm{pH}$ 5.0. After autoclaving, agar was poured into the lower portion of each (sterile) glass dish under a laminar flow hood, and each plate was then immediately covered with the plastic upper lid. After the agar solidified upon cooling, two sterile filter paper wedges ( $3 \mathrm{~cm}$ long, $2.5 \mathrm{~cm}$ width; Whatman', No. 4, $90 \mathrm{~mm}$ diam., Whatman Intl. Ltd., Maidstone, England) were gently placed over the agar surface in each plate directly opposite one another, with the narrowest portion of the wedge (point) nearly in contact with the other. In the center of the dish between each of the two wedge points, a $1 \mathrm{~cm}^{3}$ block of fungal inoculum was added, except for control plates which did not receive fungal inoculation. Seeds were sown using standard protocols involving surface sterilization followed by two DI water rinses (Zettler et al. 2005a). Using a wire inoculation loop, ca. 50-300 seeds from one of the four sources were added to the surface of the filter paper wedge. Immediately after sowing, both halves of each dish were sealed with Parafilm "M" (Pechiney Plastic Packaging, Menasha, WI, USA) to retain moisture. Seeds receiving the dark treatment were then wrapped tightly in aluminum foil to exclude light. Those that received light pre-treatment were exposed to a 12 hour photoperiod (12/12 hrs light/dark) lasting one week, then tightly wrapped in aluminum foil after this time. Both light-exposed plates and dark controls were subjected to the same incubation temperatures typical of higher altitudes in Hawaii $\left(16-19^{\circ} \mathrm{C}\right)$. Irradiance was provided by eight full-spectrum bulbs (Sylvania $\mathrm{Hg} / 32 \mathrm{~W}$ Octron 410 0K, F032/841/ECO, Danvers, MA, USA) measured at $79.9 \mu \mathrm{mol} \mathrm{m}{ }^{2} 2^{-1}$ at the plate surface. Light and incubation conditions were maintained by means of a Conviron EF7 Plant Growth Chamber (Controlled En- 
vironments, Pembina, ND, USA). Plates were inspected monthly using a dissection microscope for signs of seed germination and contamination. Contaminated plates were promptly discarded; otherwise all plates were resealed in aluminum foil and returned to experimental conditions within 15-20 min. Seedling development was assessed 258 days after sowing on a scale of 0 to 5 mentioned previously. Data were analyzed using general linear model procedures multivariate analysis of variance $(p<0.05)$ and mean separation at $\alpha=0.05$ by SPSS 12.0 for Windows subprogram (SPSS, Chicago, IL, USA). All inferential tests on germination percentages were conducted after normalizing the data using arcsine transformations.

In the second symbiotic seed germination experiment, two mycorrhizal fungus strains acquired from $P$. holochila protocorms on Molokai were tested for their ability to facilitate germination and development in vitro. The protocol was based largely on the OMA-soil/darkness method outlined previously, with three modifications: 1) one $1 \mathrm{~cm} \times 4 \mathrm{~cm}$ filter paper strip was used per plate instead of two wedges, 2) OMA harbored $8 \mathrm{~g}$ agar added instead of $7 \mathrm{~g}$ per 1 , and 3) one seed source used per plate instead of two in a combination. Five seed sources (S120, S133, S134, S139, S140) were inoculated with two fungal isolates (CBS 118625/UAMH 10545, CBS 118628/UAMH 10547). Given that the quantity of seed for each source varied, the number of replicate plates that were prepared varied. S139 yielded the fewest replicate plates $(n=4$ for each fungus), followed by S140 $(n=5), S 133$ and S134 $(n=6)$, and S120 $(n=10)$. Between $50-300$ seeds were added to the surface of each filter paper strip, and a $1 \mathrm{~cm}^{3}$ block of fungal inoculum was then added to one side of the strip (one fungus per plate per seed source). Immediately after sowing and fungal inoculation, all plates were wrapped tightly with aluminum foil and incubated in the growth chamber $\left(16-19^{\circ} \mathrm{C}\right)$ for 6 months.

\section{Asymbiotic seed germination}

Seeds of $P$. holochila were also sown on carbon-based media excluding mycorrhizal fungi (i.e., asymbiotic germination) in an effort to cultivate this species in vitro to the leaf-bearing stage. Three types of media were utilized for this purpose: 1) Knudson C Orchid Medium (Knudson 1946; Product No. K400, PhytoTechnology Laboratories, Shawnee Mission, KS, USA), 2) Murashige and Skoog basal salt mixture (M and S; Murashige and Skoog 1962; Product No. M524, PhytoTechnology Laboratories), and 3) P723 Orchid Seed Sowing Medium (Product No. P723, PhytoTechnology Laboratories). Prior to autoclaving ( $15 \mathrm{~min}$ at $121^{\circ} \mathrm{C}, 19 \mathrm{psi}$ ), the $\mathrm{pH}$ of each medium was adjusted to 5.0. Six seed sources were sown on the three media: S130, S133, S140, S142, S143, S145 (Table 1). Seeds were surface sterilized using the standard protocol described previously, and sown directly onto the surface of the agar contained within a $9 \mathrm{~cm}$ diam. plastic
Petri plate (one seed source per plate). Six replicate plates were prepared for each seed source for all three media. Immediately after sowing, each plate was wrapped twice with Parafilm "M", and then wrapped tightly in aluminum foil to exclude light. Plates were incubated at $16-19^{\circ} \mathrm{C}$ for $>12$ months. Plates were periodically inspected (e.g., usually every other month) for signs of contamination. During inspection, seeds were briefly (10-15 min) exposed to light, but were then promptly re-wrapped in aluminum foil and returned to experimental conditions. Seed germination and development were assessed on the $0-5$ stage scale previously described. At the conclusion of the study 475 days after sowing, Stage 2-4 seedlings from Knudson $\mathrm{C}$ and $\mathrm{M}$ and $\mathrm{S}$ plates - which showed little or no additional development during that time - were transferred to acidified P723 and returned to the growth chamber (darkness, $16-19^{\circ} \mathrm{C}$ ). P723 was chosen because this medium resulted in substantial seedling growth (Stage 4-5) in the other treatment, and doing so ensured that the seedlings of this critically rare species were provided with the best opportunity for continued development. Seedlings that initiated leaves (Stages 4 and 5) were illuminated and used in various preliminary experiments designed to maximize survival on soil ex vitro.

In a follow-up study, seeds from all 16 remaining sources were sown on acidified P723 used previously. Nine sources originating from Molokai (S120, S125, S130, S153, S154, S155, S156, S157, S158, and seven from Kauai (S129, S134, S140, S141, S142, S143, S146; Table 1), were surface-sterilized, sown, and incubated $>12$ months in darkness using the same procedure described above. Seed germination and development were assessed using the same $0-5$ stage scale, and percentages were based on viable seed totals. Viable seeds were recorded as those having distinct rounded or ovoid embryos that generally lacked pigmentation. After 451 days incubation in darkness, all plates harboring leaf-bearing seedlings were exposed to the 12 hour photoperiod (described previously) and incubated at $16-19{ }^{\circ} \mathrm{C}$ for 217 days. In an attempt to prompt further development under illumination, the surviving seedlings were then transferred to fresh media within raised culture vessels (Magenta ${ }^{\circ}$ GA7, Product No. C906, PhytoTechnology Laboratories; Fig. 3a). Four types of fresh media were utilized for this purpose: P723, P748 Orchid Maintenance Replate Medium (Product No. P748, PhytoTechnology Laboratories), W1.5 Advanced Orchid Medium (Western Orchids/Laboratories, Blackwood, Australia), and W2.5 Advanced Culture Medium (Western Orchids/Laboratories). Prior to autoclaving, the $\mathrm{pH}$ of each medium was adjusted to 5.0 , and $100 \mathrm{ml}$ was added to each vessel. Most (285 of 402) of the seedlings were transferred to P723 and P748 (131 and 154 seedlings, respectively). P748 was chosen for its potential to facilitate root formation because it contained higher concentrations of nutrients and other additives (S. L. Stewart, pers. comm.). Fewer (117) seedlings were placed on W1.5 and W2.5 (41 and 76, respectively) because of our unfamiliar- 
ity with these two media. Each seedling within each seed source was assigned a random number and transferred accordingly. Following transfer, the lid of each vessel was wrapped twice with Parafilm "M", returned to the growth chamber (12/12 hrs light/dark, $\left.16-19{ }^{\circ} \mathrm{C}\right)$, and incubated $>12$ months. Seedling survival on the four media was assessed after 12 months.

\section{Greenhouse establishment ex vitro}

During the course of incubation in raised culture vessels, seedlings that displayed marked leaf and/or root growth (ca. $2 \mathrm{~cm}$ in length), or were vulnerable to mold contamination, were deflasked (removed from in vitro conditions), placed on soil, and incubated in a greenhouse. The soil mixture used for this purpose was based on the potting mix applied to asymbiotically-grown Platanthera seedlings at the Atlantic Botanical Garden (M. Richards, pers. comm.). This mixture consisted of carnivorous plant mix (CP), ground tree fern (TF; Tree Fern Fiber Long, OFE International Inc., Miami, FL, USA ) and builder's sand (BS; Quikrete All-Purpose Sand, No. 1152, Quikrete International Inc., Atlanta, GA, USA) in a ratio of $4: 2: 1$ (CP:TF:BS). The composition of the carnivorous plant mix consisted of a $5: 6: 1$ ratio of peat moss (Hyponex ${ }^{\circledast}$ Canadian Sphagnum Moss, No. 15251570, Marysville, OH, USA), milled sphagnum moss (No. 20-8710, Jim's Orchid Supplies, Ft. Pierce, FL, USA), and builder's sand, respectively. Prior to mixing, the milled Sphagnum moss was added to a blender and pulverized in a dry state yielding a fine texture. After the complete soil mixture was prepared and mixed by hand, it was added to plastic pots ( $6 \mathrm{~cm}$ diam., $6 \mathrm{~cm}$ depth; Reed's Greenhouse, Spokane, WA, USA). The lower $1 / 3$ of each pot was previously filled with orchid potting mix (Special Orchid Mix, Better-Gro ${ }^{\circledast}$, Sun Bulb Co., Arcadia, FL, USA) containing raw fir bark, hardwood charcoal and coarse perlite. Each pot was placed into metal baking dishes partially filled with DI water. The dishes were then sealed with a single sheet of aluminum foil, autoclaved ( $15 \mathrm{~min}$ at $121^{\circ} \mathrm{C}, 19$ psi), and allowed to cool at ambient temperature upon removal. During autoclaving, the DI water infiltrated and saturated the orchid potting mix and soil mixture rendering a moisture-rich substrate for seedlings. Seedlings were removed from the growth chamber individually and at random depending on need (e.g., of sufficient size and/or impending mold contamination, mentioned previously), and deflasked. Root systems of seedlings were gently rinsed under DI water to remove all traces of agar clinging to surface root hairs, and added to the moist surface of the soil mixture in each pot (one seedling per pot). Root systems were completely immersed in the potting mix whereas the basal leaf (or leaves) remained exposed, permitting photosynthesis (Fig. 3b). Pots were then placed into plastic humidity domes (Ferry Morse Seed Co., Fulton, KY, USA). The lower portion of each humidity dome was filled with DI water which served to continuously saturate the potting mix in each pot. $\mathrm{Hu}$ midity domes filled with seedlings in pots were removed from the laboratory and placed in a greenhouse at Illinois College (Jacksonville, IL, USA) under natural lighting. Temperatures ranged from $5{ }^{\circ} \mathrm{C}$ (minimum) during the evening to $22^{\circ} \mathrm{C}$ (maximum) during the day. Given that P. holochila prefers cool moist bogs (600-1500 m), every effort was made to transfer the majority of seedlings to the greenhouse during cooler months (October 2010 March 2011). Seedlings were monitored weekly for leaf growth and survival. One week prior to packing for transport to Hawaii, all greenhouse-established seedling were visually inspected for potential pests (e.g., scale insects, fungal plant pathogens) by the Illinois Department of Agriculture, and an import permit from the Hawaii Department of Agriculture was also secured.

\section{Reintroduction in Hawaii}

On 5 March 2011, all soil-established greenhouse seedlings were removed from humidity domes and carefully packed into plastic covered packing trays for transport to Hawaii. To prevent pots from shuffling during transport, wads of newspaper were placed between pots along the lower portion of each tray. An additional set of seedlings that were not previously established on soil under greenhouse conditions were also packed for transport. These seedlings consisted of those that remained in the growth chamber in vitro, but had noticeable root growth (ca. 1-2 cm in length) and were deemed as potentially suitable for deflasking. Prior to transport, the roots of all in vitro seedlings were gently rinsed under DI water to remove all traces of agar, and then added to plastic fishing tackle containers lined with DI-moistened milled Sphagnum. The lids on all plastic containers were snapped shut but still allowed for ventilation (air exchange) with minimal water loss during transport. All seedlings were manually transported to Hawaii by air within 48 hours of packing as carry-on baggage. During the security screening process at the airport (STL), all seedlings were briefly exposed to radiation. Considerable care was exercised to ensure that all seedlings remained cool during transport by shielding containers from direct sunlight. Upon arrival in Hawaii, the largest seedlings were reintroduced in situ at Alakai Swamp, Kauai, and Kamakou Preserve, Molokai, on 7 and 10 March 2011, respectively. The remaining seedlings were temporarily placed in cultivation at the National Tropical Botanical Garden on Kauai, at the Lyon Arboretum on Oahu, and at Olinda Rare Plant Facility on Maui in an attempt to prompt additional growth. Most of the smaller seedlings, especially those that were deflasked without prior soil establishment, were taken to Maui because this site was located at an elevation most similar to sites where $P$. holochila is known to occur naturally. In the two natural sites, seedlings were reintroduced in microhabitats that were deemed most suitable for P. holochila based on field observations of existing plants. These mi- 
crohabitats typically consisted of slightly depressed, moist open pockets of moss beneath or adjacent to scrubby vegetation in filtered sunlight. Seedlings were released into discrete, fenced-in areas to exclude herbivores, especially wild pigs. Each seedling on Kauai was afforded with its own separate cage to discourage herbivory by recentlyintroduced deer known to jump over the existing fence at Alakai Swamp.

\section{Results}

\section{Mycorrhizal fungi and seed germination in situ}

Lateral roots of mature plants on Molokai measured at least $14 \mathrm{~cm}$ in length, and several such root systems were attached to a single plant. These roots extended
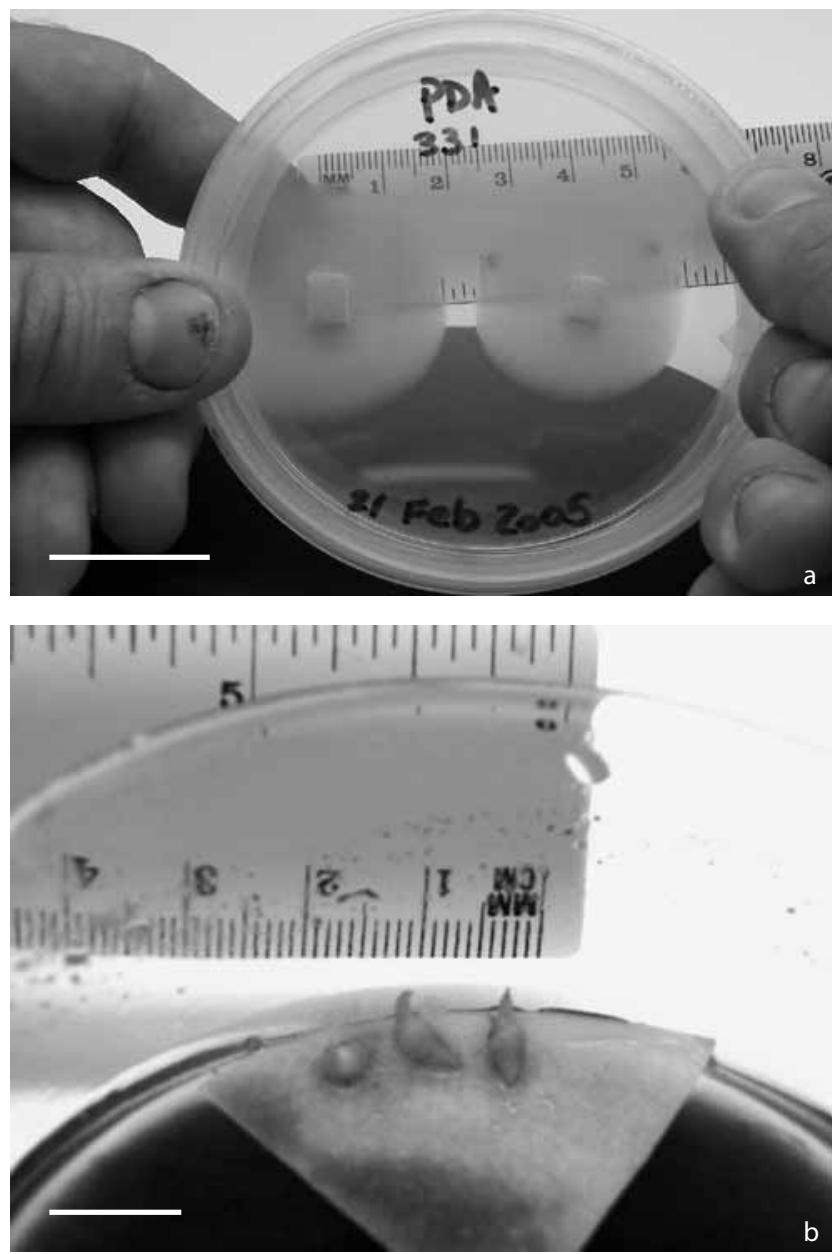

Fig. 2 Mycorrhizal fungus associate and protocorms of Platanthera holochila. (a) One of seven fungal isolates, tentatively assignable to Epulorhiza, recovered from protocorms acquired in situ on Molokai. The uniform growth of the surface mycelium and colony margins is evident, shown here on potato dextrose agar (PDA) within a $9 \mathrm{~cm}$ diam. Petri plate. This particular isolate (UAMH 10547, CBS 118628) was isolated from a Stage 4 protocorm. Scale bar $=2 \mathrm{~cm}$. (b) Three Platanthera holochila protocorms on OMA-soil, 262 days after sowing/inoculation with a mycorrhizal fungus from Florida, Epulorhiza repens (UAMH 9824). Two of the protocorms (denoted by arrows) reflect growth Stage 5 (leaf elongation). Scale bar $=1 \mathrm{~cm}$. horizontally between the upper layer of organic matter and the lower surface of living bryophytes, usually at a depth of 2-3 cm. Examination of root segments by light microscopy revealed the presence of numerous intact pelotons in all orchid samples. Repeated attempts to isolate fungi from pelotons within roots of mature plants were unsuccessful. However, of the 18 seed packets sown on Molokai in 2003, protocorms were recovered in 3 of 4 packets using S120 seed along one line. This line was located adjacent to a Hawaiian tree fern, Cibotium menziesii Hook. (Dicksoniaceae). The temperature of the soil where the protocorms were retrieved was $16.5^{\circ} \mathrm{C}$. All other seed packets sown in 2003 as well as those sown in 2004 (retrieved in November 2006), however, failed to yield protocorms. A total of 20 protocorms spanning three growth stages were recovered from the packets, 5 in
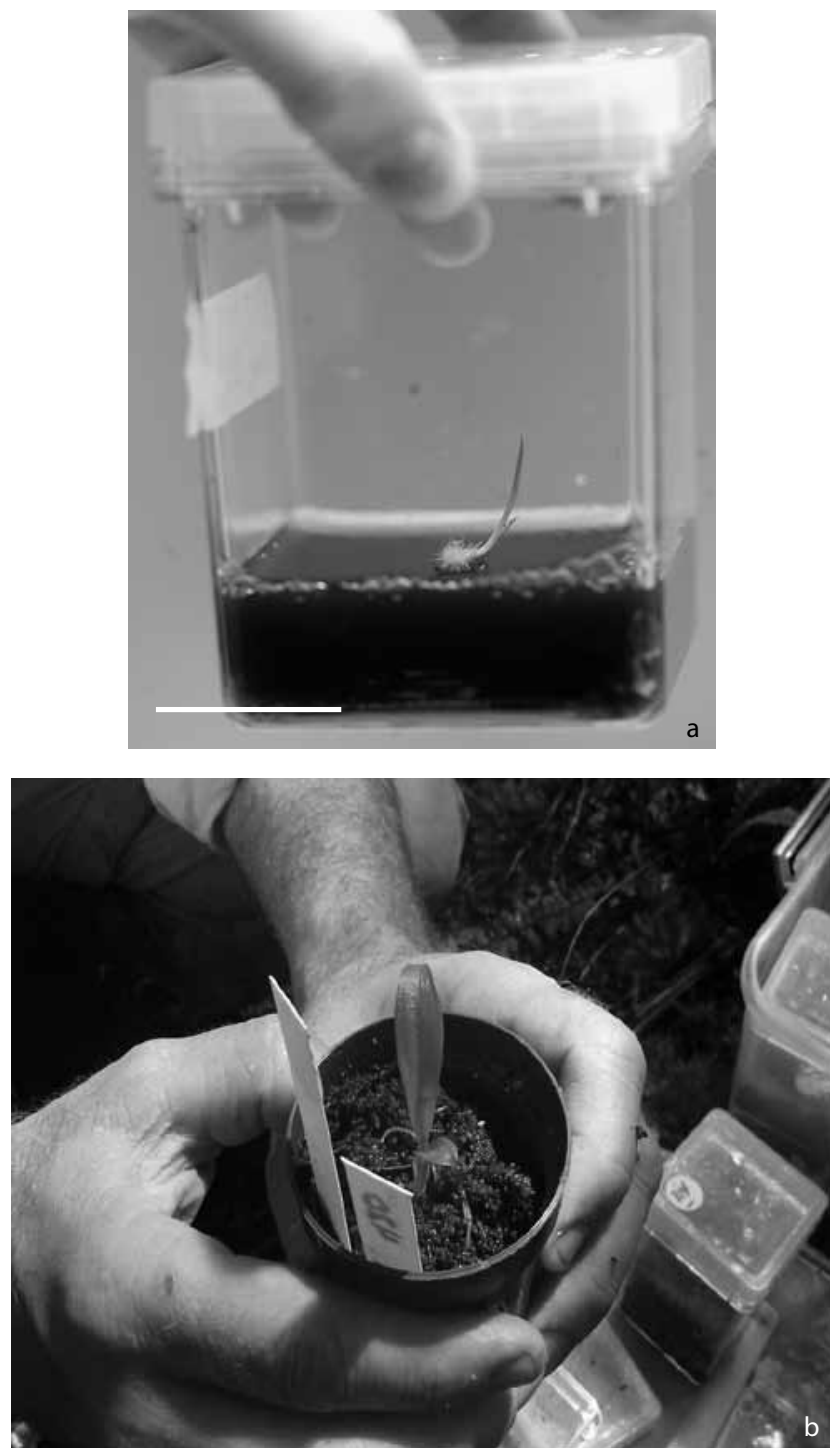

Fig. 3 Laboratory-grown seedlings of Platanthera holochila. (a) Stage 5 seedling in vitro on acidified ( $\mathrm{pH}$ 5.0) asymbiotic medium $\mathrm{P} 723$ within a raised culture vessel, 217 days after illumination and 451 days after sowing. The elongated basal leaf is clearly visible (denoted by arrow). Scale bar $=2 \mathrm{~cm}$. Photo courtesy of Chris Young. (b) Soilestablished seedling within a $6 \mathrm{~cm}$ diam plastic pot just prior to its reintroduction on Molokai. 
Stage 3, 10 in Stage 4, and 5 in Stage 5. Although pelotons were observed in all Stage 4 and 5 protocorms subjected to maceration, active hyphal growth was evident only in plates containing acidified ( $\mathrm{pH}$ 5.0) malt extract agar - the procedure applied in Illinois to protocorms in the third packet. Seven strains of a mycorrhizal fungus tentatively assignable to the anamorphic genus Epulorhiza Moore were acquired from three of these protocorms, and were deposited into the CBS culture collection as: CBS 118625, $118626,118627,118628,118629,118630,118631$. Four of the seven strains were additionally deposited in Canada as: UAMH 10545, 10546, 10547, 10548. On PDA, colony margins were sharply entire and surface mycelium was uniform in texture and cream-colored throughout (Fig. 2a), with a slightly pinkish coloration noted at the colony center. On acidified CMA (pH 5.0) and neutral CMA ( $\mathrm{pH} 7.0$ ), mean growth rate for the seven isolates was 2.63 and $1.72 \mathrm{~mm} /$ day, respectively. On acidified PDA and neutral PDA, mean growth rates were 0.52 and $0.51 \mathrm{~mm} /$ day, respectively.

\section{Symbiotic seed germination}

Seeds previously inoculated with the mycorrhizal fungus from Florida (Epulorhiza repens, UAMH 9824) germinated after 258 days for all treatments, whereas seeds incubated in the absence of the fungus (control) failed to germinate. Mean percent germination was highest $(10.62 \pm 1.2)$ for seeds sown on OMA-soil that were incubated in continuous darkness (Table 2). In contrast, seeds pre-treated with light and sown on MOM resulted in the lowest percent germination $(3.55 \pm 1.2)$. Seedling (protocorm) development was also more pronounced on OMA-soil compared to seeds sown on MOM regardless of dark versus light pre-treatment (Table 3). On OMA-soil, protocorm development culminated in the initiation/elongation of leaves (Stages 4 and 5; Fig. 2b) in both light and dark treatments, yet none of the seeds incubated on MOM resulted in seedlings beyond Stage 2 (Table 3). Statistical analysis revealed no interaction effects between agar type (OMA-soil vs. MOM) and light condition (light-pretreatment vs. continuous darkness) on seed germination, percent at Stage 4 or percent at Stage 5. However, statistical differences were detected among OMA-soil and MOM on total percent germina-
Table 2 In vitro symbiotic seed germination of Platanthera holochila using a mycorrhizal fungus acquired from Florida (Epulorhiza repens isolate 266), 258 days after sowing. Values reflect mean percent germination (+SE) comparing two different media (MOM, OMA + Soil), and light pretreatment versus dark incubation.

\begin{tabular}{|l|c|c|c|}
\hline & Light & \multicolumn{1}{c|}{ Dark } & Totals \\
\hline MOM & $3.55 \pm 1.20$ & $6.18 \pm 1.40$ & $4.70 \pm 0.94$ \\
\hline OMA + soil & $9.22 \pm 1.20$ & $10.62 \pm 1.20$ & $9.92 \pm 0.88$ \\
\hline Totals & $6.38 \pm 0.89$ & $8.68 \pm 0.94$ & $7.46 \pm 0.78$ \\
\hline
\end{tabular}

tion $\left(F_{1,30}=15.53 ; P<0.01\right)$, percent at Stage $4\left(F_{1,30}=\right.$ $11.42 ; P<0.01)$, and Stage $5\left(F_{1,30}=17.15 ; P<0.01\right)$. No significant differences were detected between light pretreatment versus dark incubation on seed germination or development. In the second symbiotic germination experiment, the use of the two Hawaiian fungal isolates (CBS 118625/UAMH 10545, CBS 118628/UAMH 10547) failed to prompt seed germination beyond Stage 1 after 6 months after sowing/inoculation.

\section{Asymbiotic seed germination}

After 475 days, seed germination and protocorm development were evident on all three asymbiotic media among three of the six seed sources (S142, S143, S145), and only one seed source (S130) failed to germinate (Table 4). Mean percent germination was highest for S145 among the three media $(48 \%, 45 \%, 12 \%$ for Knudson C, Murashige and Skoog, P723, respectively; Table 4). Fewer seeds germinated on P723, yet this was the only medium among the three that prompted seed germination to Stage 5. In the follow-up study using P723 alone, 10 of the 16 seed sources germinated, and protocorm development to an advanced stage was evident 351 days after sowing (Table 5). Seed viability exceeded $89 \%$ for all sources with one exception (S120, 85\%; Table 5). Nine of the 16 seed sources yielded leaf-bearing seedlings (Stage 4 and 5) including five acquired from the solitary Kauai plant (S129, S140, S141, S142, S143). Few (<4\%) of the viable seeds that germinated developed to Stage 5 among the seed sources, but two sources - one from Kauai (S141) and one from Molokai (S154) - yielded the highest percentages observed (3.6\% and $3.2 \%$, respectively). When seed sources between both islands were pooled, $0.9 \%$ of the

Table 3 In vitro seedling (protocorm) development of Platanthera holochila in symbiotic culture for seeds pre-treated with light versus those on continuous darkness on OMA-soil and MOM. Growth stages follow Zettler et al. (2005a), where: Stage $0=$ no germination, Stage $1=$ rhizoids evident, Stage 2 = rupture of testa by enlarged embryo, Stage 3 = appearance of shoot region, Stage $4=$ emergence of leaf from shoot, and Stage $5=$ leaf elongation. Unequal sample sizes of replicate plates $(n)$ resulted after contaminated plates were discarded.

\begin{tabular}{|l|c|c|c|c|c|c|c|c|}
\hline Treatment & $\boldsymbol{n}$ & \# Seeds & \# Stage 0 & \# Stage 1 & \# Stage 2 & \# Stage 3 & \# Stage 4 & \# Stage 5 \\
\hline MOM light & 9 & 435 & 420 & 1 & 14 & 0 & 0 & 0 \\
\hline MOM dark & 7 & 327 & 307 & 5 & 15 & 0 & 0 & 0 \\
\hline OMA-soil light & 9 & 455 & 414 & 0 & 7 & 4 & 9 & 21 \\
\hline OMA-soil dark & 9 & 351 & 315 & 1 & 13 & 6 & 3 & 13 \\
\hline
\end{tabular}


Table 4 Asymbiotic germination of Platanthera holochila on three media, 475 days after sowing and incubation in darkness at $16-19{ }^{\circ} \mathrm{C}$ Growth stages follow Zettler et al. 2005a, where: Stage $0=$ no germination, Stage $1=$ rhizoids evident, Stage $2=$ rupture of testa by enlarged embryo, Stage 3 = appearance of shoot region, Stage 4 = emergence of leaf from shoot, and Stage 5 = leaf elongation.

\begin{tabular}{|c|c|c|c|c|c|c|c|c|c|c|c|}
\hline Medium ${ }^{1}$ & $\begin{array}{c}\text { Seed } \\
\text { Source }^{2}\end{array}$ & $n^{3}$ & \# Seeds & \# Stage 0 & \# Stage 1 & \# Stage 2 & \# Stage 3 & \# Stage 4 & \# Stage 5 & \# lost ${ }^{4}$ & $\begin{array}{c}\text { Mean \% } \\
\text { Germination }\end{array}$ \\
\hline \multirow{6}{*}{ Knudson C } & $\mathrm{S} 130$ & 5 & 64 & 64 & - & - & - & - & - & - & 0.0 \\
\hline & S133 & 6 & 154 & 147 & 2 & 2 & 0 & 1 & - & 2 & 4.5 \\
\hline & S140 & 6 & 194 & 189 & 0 & 1 & 1 & - & - & 3 & 2.3 \\
\hline & S142 & 5 & 89 & 86 & 2 & 1 & - & - & - & 0 & 3.4 \\
\hline & $\mathrm{S} 143$ & 6 & 113 & 109 & 0 & 0 & 1 & - & - & 3 & 3.5 \\
\hline & S145 & 5 & 128 & 67 & 1 & 30 & 20 & - & - & 10 & 47.7 \\
\hline \multirow{6}{*}{$M$ and $S$} & $\mathrm{~S} 130$ & 6 & 54 & 54 & - & - & - & - & - & - & 0.0 \\
\hline & $\mathrm{S} 133$ & 6 & 78 & 75 & 1 & 1 & - & - & - & 1 & 3.8 \\
\hline & S140 & 5 & 78 & 78 & - & - & - & - & - & - & 0.0 \\
\hline & $\mathrm{S} 142$ & 6 & 114 & 104 & 1 & 4 & 4 & - & - & 1 & 8.8 \\
\hline & $\mathrm{S} 143$ & 6 & 129 & 125 & 0 & 2 & - & - & - & 2 & 3.1 \\
\hline & S145 & 5 & 105 & 58 & 0 & 43 & 3 & - & - & 1 & 44.8 \\
\hline \multirow{6}{*}{ P723 } & $\mathrm{S} 130$ & 6 & 76 & 76 & - & - & - & - & - & - & 0.0 \\
\hline & $\mathrm{S} 133$ & 6 & 98 & 98 & - & - & - & - & - & - & 0.0 \\
\hline & $\mathrm{S} 140$ & 6 & 222 & 222 & - & - & - & - & - & - & 0.0 \\
\hline & $\mathrm{S} 142$ & 5 & 90 & 89 & 1 & - & - & - & - & 0 & 1.1 \\
\hline & S143 & 6 & 184 & 177 & 0 & 0 & 0 & 0 & 2 & 5 & 3.8 \\
\hline & S145 & 6 & 167 & 147 & 0 & 0 & 0 & 5 & 13 & 2 & 12.0 \\
\hline
\end{tabular}

${ }^{1}$ Knudson C = Knudson C Orchid Medium (Knudson 1946), M and S = Murashige and Skoog basal salt mixture (Murashige and Skoog 1962), P723 = P723 Orchid Seed Sowing Medium (Product No. P723, PhytoTechnology Laboratories). The agar pH of all three media was lowered to 5.0 prior to autoclaving. ${ }^{2}$ Seed sources were obtained from Kauai and Molokai populations listed in Table 1. ${ }^{3}$ Number of replicate Petri plates for a given treatment; unequal subsample sizes resulted after contaminated plates were discarded. ${ }^{4}$ Reflects the number of seedlings that were counted as dead (e.g., dark brown in color).

viable Kauai seeds developed to Stage 5 compared to $1.3 \%$ for Molokai seeds (Table 5). A total of 423 leaf-bearing (Stage 4 and 5) seedlings were acquired in the follow-up study, including 47 in Stage 5 derived from the solitary Kauai specimen.

At the onset of illumination (451 days after sowing), 402 leaf-bearing seedlings from the follow-up study had survived during dark incubation and were colorless (whitish), lacking in pigmentation. Within one week of illumination, the shoot region and basal leaf were noticeably greener in color. After 12 months incubation on the fresh media in raised culture vessels, 363 of 402 (90.3\%) of the seedlings had survived. Seedling survival was highest on P723 (127/131 or 96.9\%), followed by W2.5 (72/76 or $94.7 \%)$, W1.5 (36/41 or $87.8 \%)$, and P748 (128/154 or $83.1 \%)$.

\section{Greenhouse establishment ex vitro}

During an 18 week period (October 2010 through February 2011), a total of 77 seedlings were deflasked, transferred to potting soil, and incubated in the greenhouse. In March 2011, at the conclusion of the study, 44 seedlings (57.1\%) had survived. Mean length of basal leaves on surviving seedlings was $2.3 \mathrm{~cm}$ upon soil transfer, and $3.7 \mathrm{~cm}$ at the conclusion of the study, indicating that the leaves grew a mean of ca. $1.4 \mathrm{~cm}$ during this time.

\section{Reintroduction in Hawaii}

A total of 85 seedlings were transported to Hawaii on 6 March 2011, but one seedling destined for the National Tropical Botanical Garden did not survive transport. The composition of these seedlings consisted of 32 derived from early preliminary experiments involving asymbiotic germination with Knudson $\mathrm{C}, \mathrm{M}$ and $\mathrm{S}$ and P723, and 53 from the follow-up study (germination on acidified P723 with 16 remaining seed sources). Of these 53 from the follow-up study, 24 remained on P723 throughout in vitro incubation, 13 were transferred to P748, and the remaining number were placed on the Australian media (9 and 7 seedlings on W 1.5 and W2.5, respectively). A minimum of 3.1 years ( 1,140 days) was required for the propagation from of $P$. holochila using asymbiotic media, from seed sowing to reintroduction. Of the 84 surviving seedlings, 17 were reintroduced in situ: 8 plants from seed sources S141, S142, S143 onto Kauai; 9 plants from S154, S158, S145 onto Molokai. Thus, all seedlings reintroduced in situ originated from seed acquired from the same source population. Although 7 additional seedlings were also of suitable size for immediate reintroduction, the decision 
Table 5 In vitro asymbiotic seed germination and development of Platanthera holochila on acidified (pH 5.0) P723, 351 days after sowing and incubation in darkness at $16-19^{\circ} \mathrm{C}$. Growth stages follow Zettler et al. $2005 \mathrm{a}$, where: Stage $0=$ no germination, Stage $1=$ rhizoids evident, Stage 2 = rupture of testa by enlarged embryo, Stage $3=$ appearance of shoot region, Stage $4=$ emergence of leaf, and Stage $5=$ leaf elongation.

\begin{tabular}{|c|c|c|c|c|c|c|c|c|c|c|c|}
\hline $\begin{array}{l}\text { Seed } \\
\text { Source }{ }^{1}\end{array}$ & $\begin{array}{l}\text { Island/ } \\
\text { Date }^{2}\end{array}$ & $n^{3}$ & \# Seeds & \# Viable $(\%)^{4}$ & \# Stage 0 & \# Stage 1 & \# Stage 2 & \# Stage 3 & \# Stage 4 & \# Stage 5 & $\begin{array}{c}\text { Mean \% } \\
\text { Stage } 5\end{array}$ \\
\hline $\mathrm{S} 120$ & M 2002 & 6 & 122 & $104(85.2)$ & 101 & 0 & 0 & 3 & - & - & 0.0 \\
\hline S125 & M 2002 & 17 & 1,075 & $1,016(94.5)$ & 1,016 & - & - & - & - & - & 0.0 \\
\hline S130 & M 2003 & 9 & 382 & 378 (98.9) & 378 & - & - & - & - & - & 0.0 \\
\hline S153 & M 2006 & 22 & 5,627 & $5,052(89.8)$ & 5,021 & 1 & 18 & 0 & 0 & 12 & 0.2 \\
\hline S154 & M 2006 & 35 & 8,180 & 7,804 (95.4) & 7,387 & 7 & 71 & 21 & 66 & 252 & 3.2 \\
\hline S155 & M 2006 & 16 & 1,551 & $1,514(97.6)$ & 1,514 & - & - & - & - & - & 0.0 \\
\hline S156 & M 2006 & 7 & 157 & $151(96.2)$ & 151 & - & - & - & - & - & 0.0 \\
\hline S157 & M 2006 & 17 & 2,508 & 2,466 (98.3) & 2,456 & 0 & 0 & 6 & 2 & 2 & 0.1 \\
\hline \multirow[t]{2}{*}{ S158 } & M 2006 & 15 & 1,811 & $1,743(96.2)$ & 1,732 & 0 & 0 & 7 & 4 & - & 0.0 \\
\hline & M Totals & & 21,413 & $20,228(94.5)$ & 19,756 & 8 & 89 & 37 & 72 & 266 & 1.3 \\
\hline S129 & K 2003 & 11 & 442 & 406 (91.9) & 380 & 3 & 4 & 4 & 8 & 7 & 1.7 \\
\hline S134 & K 2004 & 3 & 92 & $85(92.4)$ & 85 & - & - & - & - & - & 0.0 \\
\hline S140 & K 2005 & 18 & 2,208 & $2,135(96.7)$ & 2,083 & 11 & 19 & 9 & 12 & 1 & 0.6 \\
\hline S141 & K 2005 & 11 & 767 & 727 (94.8) & 663 & 2 & 9 & 11 & 16 & 26 & 3.6 \\
\hline S142 & K 2005 & 5 & 649 & $621(95.7)$ & 579 & 8 & 22 & 0 & 0 & 12 & 1.9 \\
\hline S143 & K 2005 & 10 & 977 & $936(95.1)$ & 923 & 3 & 6 & 1 & 2 & 1 & 0.1 \\
\hline \multirow[t]{2}{*}{ S146 } & K 2006 & 2 & 119 & $111(93.3)$ & 111 & - & - & - & - & - & 0.0 \\
\hline & KTotals & & 5,254 & $5,021(95.6)$ & 4,824 & 27 & 60 & 25 & 38 & 47 & 0.9 \\
\hline Totals & & & 26,667 & $25,249(94.7)$ & 24,580 & 35 & 149 & 62 & 110 & 313 & 1.2 \\
\hline
\end{tabular}

${ }^{1}$ Seed sources were obtained from Kauai and Molokai populations listed in Table 1. ${ }^{2} \mathrm{M}=$ Molokai seed and year collected, $\mathrm{K}=\mathrm{Kauai}$ seed and year collected. ${ }^{3}$ Number of replicate plates varied due to differences in seed quantity among the 16 sources. ${ }^{4}$ Seed viability was assessed visually by dissection microscopy. Seeds containing embryos that appeared robust, white/colorless, and oval in shape were considered viable.

was made to retain these plants in captivity because the seed source (S140) was of questionable origin (Table 1). Of the 68 seedlings placed into cultivation, 6 were deposited at the National Tropical Botanical Garden, 14 at the Lyon Arboretum, and 47 at the higher-elevation site on Maui (Olinda Rare Plant Facility). As of 2 May 2011, 3 of the 6 plants taken to NTBG had survived (M. DeMotta, pers. comm.). Of the 8 reintroduced on Kauai, 6 seedlings showed signs of visible growth on 28 April 2011. On Molokai, 8 of the 9 seedlings appeared to have survived as of 31 March 2011. At the time of this writing (24 May 2011) ca. $80 \%$ of the seedlings at Olinda on Maui remained alive, and ca. $60 \%$ have shown visible growth since March 2011. The other 40\% have remained approximately the same size (A. Palomino, pers. comm.). A synopsis of our protocol for growing $P$. holochila from seed leading to seedling establishment in situ is presented in Appendix 1.

\section{Discussion}

The highlight of this study was the reintroduction of Platanthera holochila - a critically rare terrestrial orchid with a notorious reputation for resisting protocols directed at its propagation from seed. In retrospect, it is not surprising that the early attempts (pre-2002) were unsuccessful given that temperate terrestrial orchids generally have fastidious germination requirements compared to their tropical epiphytic counterparts. In the late 1970s, symbiotic seed germination re-emerged in Australia as a powerful tool that could be used to propagate terrestrial orchids from seed, including rare and/or problematic taxa (Warcup 1973; Clements and Ellyard 1979). Moreover, seedlings reared with mycorrhizal fungi grew rapidly in vitro, and often had modest survival rates upon deflasking. Shortly thereafter, this technique was applied to terrestrial orchids in North America (e.g., Smreciu and Currah 1989; Anderson 1991), including species of Platanthera threatened with extinction (Zettler and McInnis 1992). Results were generally promising provided that compatible fungi were obtained. Most fungi acquired for this purpose were isolated from root systems of mature plants until Rasmussen and Whigham's seed baiting technique made it possible for fungi to be obtained from diminutive subterranean protocorms. For the first time, the mycorrhizal fungi that triggered seed germination in situ could be recovered, identified, and utilized for conservation.

When it became clear that symbiotic seed germination had merit for $P$. holochila's immediate recovery, the deci- 
sion was made to use a mycorrhizal fungus from Florida (UAMH 9824) with a well-established track-record for prompting germination in a wide range of taxa, including Platanthera species on the mainland (Zettler 2008). In this manner, symbiotic protocols could be developed and perfected in advance until mycorrhizal fungi from Hawaii could be secured and used instead. Indeed, initial results were promising. Compared to similar studies (e.g., Zettler and McInnis 1992; Zettler and Hofer 1998), germination percentages seemed low $(<17 \%)$, but seeds inoculated with this fungus quickly developed to Stage 5 on standard oat-based media adjusted to a low $\mathrm{pH}$ (Zettler et al. 2005a), leading to further work. In follow-up experiments with the Florida mycorrhizal fungus (the present study), we attempted to stimulate seed germination by exposing seeds to light-pretreatment as reported for Dactylorhiza majalis in Europe (Rasmussen et al. 1990) and Platanthera integrilabia in North America (Zettler and McInnis 1994). Because seed germination in another terrestrial orchid (Tipularia discolor) was also stimulated by the presence of decomposing wood (Rasmussen and Whigham 1998), we decided to add soil/organic matter from Molokai to the oat-based medium. However, seed germination percentages remained low (3-11\%), and no significant differences were detected between light pretreatment versus dark incubation on seed germination or development. The addition of soil, however, did have a statistically positive effect on both germination and development.

Concurrent to improving our symbiotic protocol, we set out to recover $P$. holochila's mycorrhizal fungi in situ. Although we observed numerous intact pelotons in root systems of mature plants and protocorms alike, hyphae from MMN-immersed pelotons could not be enticed to grow despite repeated attempts, even when the $\mathrm{pH}$ was lowered to 5.0. As a last resort, the remaining seven protocorms from the third seed packet were then dissected in half and immersed in malt extract agar instead of MMN alone. This procedure worked, yielding a slow-growing fungus resembling published descriptions of the ubiquitous anamorph Epulorhiza (Currah et al. 1990, 1997a,b), with closest resemblance to E. inquilina among the established taxa (Currah et al. 1997b). Different strains from this fungus were deposited into two international culture collections (CBS, UAMH) for safekeeping and future use, and symbiotic germination experiments quickly ensued. Two of the newly acquired strains (CBS 118625/UAMH 10545, CBS 118628/UAMH 10547) failed to prompt seed germination in vitro beyond Stage 1 . We then attempted symbiotic germination with the other five Hawaiian isolates, but these isolates were equally ineffective (K. McDonald and L.W. Zettler, unpub. data). As to why the seven Hawaiian isolates did not facilitate germination remains unknown, but poor seed quality may be ruled out because the same seed sources utilized in symbiotic experiments (S140, S141, S142, S143, S145) yielded protocorms upon sowing on asymbiotic media (P723) in the subsequent study. Despite our inability to propagate $P$. holochila with the Hawaiian isolates, we suspect that these fungi are of some physiological significance to the orchid because they were acquired from intact pelotons. Other researchers may have more success with these strains using other methods, and the deposition of the cultures into CBS and UAMH will now make this possible. Given that the flora of Hawaii has a large number of endemics, it is conceivable that these fungal strains represent a unique taxonomic assemblage. The use of molecular markers to more fully explore the taxonomic identity of these $\mathrm{Ha}$ waiian isolates is especially encouraged. We also advocate further work aimed at recovering more isolates from living plant tissues, provided that doing so is carried out in a manner that does not jeopardize the small number of existing plants and/or severely limits the species' ability to spawn a new generation of seedlings.

The use of asymbiotic media to propagate $P$. holochila was considered a necessary step towards our long-term goal of reintroduction. Even if germination and development could be achieved in vitro, however, establishing asymbiotic seedlings on soil upon deflasking represented a serious challenge. Our decision to forge ahead was inspired, in part, by recent success in cultivating another rare Platanthera species ( $P$. integrilabia) at the Atlanta Botanical Garden using various potting mixes (Matt Richards, pers. comm.). Of the three asymbiotic media we tested initially, acidified P723 was clearly more effective at facilitating seedling development even though fewer seeds germinated on this medium (Table 4). Equally striking were differences observed between the six seed sources tested, namely the high germination percentages of S145 seed. Why differences were noted in germination among the seed sources remains unclear, but seed quality might have been influenced by the timing involved when capsules were detached from the inflorescence. Taken together, the decision was made to sow seeds from all remaining sources in storage on P723 in a follow-up study aimed at acquiring a large number of leaf-bearing seedlings for reintroduction purposes. Nearly one year after sowing (351 days), more than 400 leaf-bearing seedlings were obtained in vitro from seed sources acquired on both Kauai and Molokai (Table 5). Despite the development of leaves, we opted to incubate these seedlings another 100 days in darkness because we assumed that protocorms of this terrestrial orchid would not be exposed to light under natural conditions. After 451 days, most (402 of 423) of the leaf-bearing seedlings had survived and were then subjected to illumination, resulting in further leaf elongation, green pigmentation, and conceivably photosynthesis. Upon transfer to fresh media in raised vessels 217 days after illumination, seedling development progressed, but survival was highest (96.9\%) on acidified P723 - the same medium used at the onset to prompt germination. Lower survival rates on P748, W1.5, and W2.5 might be attributed to the inability of some seedlings to acclimate to the new medium upon transfer. Surprisingly, P748 - chosen 
because of its reputation for inducing root formation resulted in the lowest seedling survival observed (83.1\%).

Of the 85 seedlings that were ultimately transported to Hawaii, 53 originated from the follow-up study involving P723. Thus, a minimum of 3.1 years is required for the propagation of $P$. holochila from seed germination to seedling reintroduction using asymbiotic medium P723. If symbiotic techniques had been an option, this time frame might have been considerably shortened. For example, Zettler and McInnis (1992) established mycorrhizal seedlings of Platanthera integrilabia on soil 388 days after sowing, and similar results have also been reported for related genera in North America (e.g., Habenaria repens; Stewart and Zettler 2002). While an extended period of time (3.1 years) may seem insignificant when the ultimate goal is to reintroduce $P$. holochila seedlings in situ, prolonged incubation increases the likelihood that some seedlings will succumb to contaminating microorganisms (e.g., Penicillium). Indeed, despite our best efforts to minimize contaminants (e.g., double-wrapping plates with Parafilm "M"), conidia of common molds did occasionally gain entry onto the surface of sugar-rich asymbiotic medium, forcing us to deflask some seedlings prematurely. This problem might have been avoided had the vessels been equipped with screw cap lids, but our set-up apparently allowed for some degree of airflow and perhaps afforded the seedlings with gas exchange.

Survival rates for deflasked terrestrial orchid seedlings are generally low without the presence of mycorrhizal fungi (e.g., Anderson 1991), therefore it is not surprising that nearly half $(42.9 \%)$ of the seedlings perished upon transfer to the greenhouse. At the time of soil establishment (October-February), temperatures in the greenhouse ranged from $5-22^{\circ} \mathrm{C}$. Cooler temperatures may have had a positive effect on survival considering that minimum temperatures at Alakai Swamp (Kauai), for example, have been known to approach freezing on occasion during winter months. Seedling survival also might have been lower had we not previously sterilized the potting mix, rendering the seedlings' new environment pathogen-free, at least initially. Flooding the lower portion of the humidity domes with water prevented the soil mix from drying out which also may have also played a beneficial role on survival.

\section{Reproductive biology of Platanthera holochila}

Prior to March 2011, 33 individual plants were known to remain on Molokai (25), Maui (7), and Kauai (1). To meet the stability criteria outlined by the U.S. Fish and Wildlife Service's recovery plan (2009), each P. holochila population should harbor at least 50 mature individuals. Attaining this goal will probably require active, longterm management of existing populations coupled with the establishment of laboratory-grown seedlings. Clearly, understanding $P$. holochila's reproductive biology will be crucial to both processes. Of the information acquired so far (Zettler et al. 2005a; present study), several assumptions can now be made concerning this species' reproductive biology, especially involving fruit set and seed germination.

Mature plants typically flower each year, and several inflorescences may arise from a solitary clump. It is not uncommon for each inflorescence to have 25 flowers. Platanthera holochila is most likely self-pollinated rather than cross-pollinated, although bagging experiments are needed to test this hypothesis. MacCaughey (1916) alluded to self-pollination in all three Hawaiian endemic orchids given the scarcity of insects associated with native Hawaiian forests coupled with regularity of fruit set. Indeed, most flowers on $P$. holochila inflorescences regularly develop mature capsules. These capsules yield monoembryonic seeds and most (>85\%) appear to have viable embryos upon visual inspection. Seeds of $P$. holochila are larger in size compared to other North American Platanthera species (e.g., P. ciliaris, $P$. clavellata, $P$. integrilabia, P. leucophaea; L.W. Zettler, pers. obs.). Yoder et al. (2010) reported that $P$. holochila seeds had the highest fresh initial mass, dry mass, and water mass among the 10 North American orchid taxa they studied. Large seed size coupled with small (12-14 mm) capsule length (MacCaughey 1916; pers. obs.) suggests that $P$. holochila yields relatively few seeds per capsule compared to other orchids. Although seed number per capsule has yet to be fully established for P. holochila, two mature capsules acquired from a $P$. holochila inflorescence on Maui yielded a mean of 935 seeds (L.W. Zettler, unpub. data). Thus, it is conceivable that this species releases ca. 1000 seeds per capsule. According to Arditti (1992), orchids produce between 1000 to four million seeds per capsule, depending on the species. While $P$. holochila's seed output may appear comparably low, one inflorescence with 25 capsules has the potential to produce 25,000 seeds in a given year. By comparison, $P$. integrilabia - a rare, cross pollinated species - yielded more (3433) seeds per capsule, but fewer $(16,000)$ seeds per plant given that fewer (4.7) capsules developed to maturity (Zettler et al. 1996). Thus, low seed number per capsule might be offset by $P$. holochila's ability to produce a substantial number of mature capsules on a single inflorescence.

Although few seeds readily germinated $(>20 \%)$, the percentage of seeds that developed to advanced-stage protocorms (ca. 2-3\%) closely parallels percentages reported for other Platanthera species involving in vitro symbiotic germination (Zettler and McInnis 1992; Zettler and Hofer 1998). Seeds develop to sizable (Stage 5) protocorms in as little as one year upon release from capsules. It is not known if seeds can remain dormant in viable condition for $>1$ year in situ. Protocorms are fully mycotrophic and subterranean initially, and probably initiate photosynthesis after 1-2 years. The time required for seedlings to reach maturity is not known, but it seems reasonable that at least 5 years is required, similar to other Platanthera species in North America (e.g., P. leucophaea; 
Case 1987; Bowles and Bell 1999). At maturity, P. holochila supplements photosynthesis with mycotrophy (or vice versa) depending on its nutritional needs. Longevity remains to be determined, but a mature plant possibly lives at least 10 years, perhaps more. During this time a solitary plant may produce multiple clumps (clones) in close proximity to the original, with each clump bearing one or more inflorescences.

In conclusion, artificial seed propagation and reintroduction will likely be critical to the immediate and long-term recovery of this endangered species. Assuming that our reintroduced, asymbiotically-grown seedlings survive to maturity, and until symbiotic germination with Hawaiian mycorrhizal fungi can be achieved, the protocol described herein offers the best hope for the conservation of this unique orchid. In addition to developing more effective propagation protocols, we urge future researchers to consider reintroducing seedlings into suitable habitats higher in elevation given the expected climate change projections this century $\left(5.8^{\circ} \mathrm{C}\right.$ increase; see Hansen et al. 2001). These areas should take into account the soil temperatures suitable for seed germination in situ (e.g., $16.5^{\circ} \mathrm{C}$ ). Furthermore, we recommend that seedling reintroductions be restricted only to the same seed donor island, at least until genetic studies verify the homogeneity of the existing populations. On Oahu where P. holochila is now extinct, reintroductions should involve seedlings derived from either Kauai or Molokai seed. Efforts are currently underway to propagate $P$. holochila from seed obtained from the existing Maui population using this asymbiotic protocol.

\section{Acknowledgements}

We are grateful to many people and organizations who have contributed to this project. Funding support was graciously provided by the San Diego County Orchid Society, Stephen and Katherine Tillery, Illinois College's Faculty-Student Research Committee, Kona Orchid Society, Dai Fukuji Orchid Club, Illinois Orchid Society, Prairie State Orchid Society, and the Central Chapter of the Illinois Native Plant Society. We warmly thank the following people for technical support: Hank Oppenheimer (PEPP-Maui), Wendy Kishida (PEPP-Kauai), Elizabeth Rellinger Zettler (Illinois College), Saundra Turner (St. Cloud St. Univ.), Yoneo Sagawa (Univ. Hawaii-Manoa), F. William Zettler (Univ. Florida), Scott Stewart (Kankakee Community College, IL), Matt Richards (Atlanta Botanical Garden), Anna Palomino (Olinda Rare Plant Facility, Maui), Chris Young (The State-Journal Register, Springfield, IL), Andy Stice (Illinois College), Curtis Braffet (Illinois Dept. Agriculture), Tina Lau (The Nature Conservancy, Molokai), Ane Bakutis (PEPP-Molokai), Marie Bruegmann (U.S. Fish and Wildlife Service), and Michelle Clark (U.S. Fish and Wildlife Service). Thanks are also extended to the staff at the National Tropical Bo- tanical Garden for their feedback and assistance: Chipper Wichman, David Burney and Mike DeMotta. This project would not be possible without the hard work and dedication of our team of current and former Illinois College students: Shanna David, Tegan Fugate, Lillian MollerJacobs (Penn. St. Univ.), James (JJ) Sadler (Univ. Florida), Kris McDonald (Univ. Illinois - Springfield), Becky Turnquist, Sarah Hopkins (Univ. Alaska - Fairbanks), Sarah Poulter (Southern Illinois Univ. - Edwardsville), Darcie Dennis (Univ. Southern Mississippi), Ashley Yates, Amanda Morrison, and Djenan (Mouna) Soumahoro.

\section{REFERENCES}

Anderson AB (1991) Symbiotic and asymbiotic germination and growth of Spiranthes magnicamporum (Orchidaceae). Lindleyana 6: 183-186.

Arditti J (1992) Fundamentals of orchid biology. John Wiley and Sons, NY.

Bowles ML, Bell TJ (1999) Recovery strategies and delisting criteria for Platanthera leucophaea, Asclepias meadii, Lespedeza leptostachya, Dalea foliosa and Cirsium pitcheri. Report to the Illinois Endangered Species Protection Board, The Morton Arboretum, Lisle, IL, USA.

Case FW (1987) Orchids of the Western Great Lakes Region. Revised edition. Cranbrook Inst Sci Bull 48: 251.

Clements MA, Ellyard RK (1979) The symbiotic germination of Australian terrestrial orchids. Am Orchid Soc Bull 48: 810-816.

Clements MA, Muir H, Cribb PJ (1986) A preliminary report on the symbiotic germination of European terrestrial orchids. Kew Bull 41: 437-445.

Currah RS, Sigler L, Hambleton S (1987) New records and new taxa of fungi from the mycorrhizae of terrestrial orchids of Alberta. Can J Bot 65: 2473-2482.

Currah RS, Smreciu EA, Hambleton S (1990) Mycorrhizae and mycorrhizal fungi of boreal species of Platanthera and Coeloglossum (Orchidaceae). Can J Bot 68: 1171-1181.

Currah RS, Zelmer CD, Hambleton S, Richardson KA (1997a) Fungi from orchid mycorrhizas. In: Arditti J, Pridgeon AM (eds) Orchid Biology: Reviews and Perspectives, VII. Kluwer. Academic Publishers, UK, pp 117-170.

Currah RS, Zettler LW, McInnis TM (1997b) Epulorhiza inquilina sp. nov. from Platanthera (Orchidaceae) and a key to Epulorhiza species. Mycotaxon 61: 335-342.

Dixon K (1987) Raising terrestrial orchids from seed. In: Harris WK (ed) Modern orchid growing for pleasure and profit. Orchid Club of S. Australia, Inc. Adelaide, S. Australia, pp 47-100.

Hansen AJ, Nelson RP, Dale VH, Flather CH, Iverson LR, Currie DJ, Shafer S, Cook R, Bartlein PJ (2001) Global change in forests: responses of species, communities, and biomes. BioScience 51: 765-779.

Knudson L (1946) A new nutrient solution for orchid seed germination. Am Orchid Soc Bull 15: 214-217.

MacCaughey V (1916) The orchids of Hawaii. The Plant World 19: 350-355.

Marx DH (1969) The influence of ectotrophic mycorrhizal fungi on the resistance of pine roots to pathogenic infections. Part I. Antagonisms of mycorrhizal fungi to root pathogenic fungi and soil bacteria. Phytopath 59: 153-163.

Murashige T, Skoog F (1962) A revised medium for rapid growth and bioassays with tobacco tissue cultures. Physiol Plant 15: 473-497. 
Rasmussen HN (1995) Terrestrial orchids: from seed to mycotrophic plant. Cambridge University Press, Cambridge.

Rasmussen HN, Anderson TF, Johansen B (1990) Light stimulation and darkness requirement for the symbiotic germination of Dactylorhiza majalis in vitro. Physiol Plant 79: 226-230.

Rasmussen HN, Whigham DF (1993) Seed ecology of dust seeds in situ: a new study technique and its application to terrestrial orchids. Am J Bot 80: 1374-1378.

Rasmussen HN, Whigham DF (1998) Importance of woody debris in seed germination of Tipularia discolor (Orchidaceae). Am J Bot 85: 829-834.

Sakai AK, Wagner WL, Mehrhoff LA (2002) Patterns of endangerment in the Hawaiian flora. Syst Biol 51(2): 276-302.

Saransan V, Cripps R, Ramsay MM, Atherton C, McMichen M, Prendergast G, Roundtree JK (2006) Conservation in vitro of threatened plants-progress in the past decade. In Vitro Cell Dev Biol - Plant 42: 206-214.

Smreciu EA, Currah RS (1989) Symbiotic germination of seeds of terrestrial orchids of North America and Europe. Lindlelyana 1: 6-15.

Stewart SL, Zettler LW (2002) Symbiotic germination of three semi-aquatic rein orchids (Habenaria repens, H. quinqueseta, H. macroceratitis) from Florida. Aquatic Bot 72: 25-35.

Stewart SL, Zettler LW, Minso J, Brown PM (2003) Symbiotic germination and reintroduction of Spiranthes brevilabris Lindley, an endangered orchid native to Florida. Selbyana 24: 64-70.

Sugii NC (2011) The establishment of axenic seed and embryo cultures of endangered Hawaiian plant species: special review of disinfestations protocols. In Vitro Cell Dev Biol - Plant 47: 157-169.

U.S. Fish and Wildlife Recovery Plan (2009) 5-year review (Platanthera holochila). http:/ecos.fws.gov/docs/five_year_review /doc2447.pdf.

Walker JH (1994) Intrepid trio: three orchid species arrived in Hawaii unassisted. Now one of them is in trouble. Amer Hort (December issue): $38-41$.

Warcup JH (1973) Symbiotic germination of some Australian terrestrial orchids. New Phytol 72: 387-392.

Yoder JA, Imfeld SM, Heydinger DJ, Hart CE, Collier MH, Gribbins KM, Zettler LW (2010) Comparative water balance profiles of Orchidaceae seeds for epiphytic and terrestrial taxa endemic to North America. Pl Ecol 211: 7-17.

Zettler LW (2008) An overview of the orchid fungal association, and its application to orchid conservation in the Americas. Proceedings of the 19th World Orchid Conference, Miami, FL, pp 315-318.

Zettler LW, Ahuja NS, McInnis TM (1996) Insect pollination of the endangered monkey-face orchid (Platanthera integrilabia) in McMinn County, Tennessee - one last glimpse of a once common spectacle. Castanea 61: 14-24.

Zettler LW, Hofer CJ (1998) Propagation of the little club-spur orchid (Platanthera clavellata) by symbiotic seed germination, and its ecological implications. Env Exp Bot 39: 189-195.

Zettler LW, McInnis TM (1992) Propagation of Platanthera integrilabia (Correll) Luer, and endangered terrestrial orchid, through symbiotic seed germination. Lindleyana 7: 154-161.

Zettler LW, McInnis TM (1994) Light enhancement of symbiotic seed germination and development of an endangered terrestrial orchid (Platanthera integrilabia). Plant Sci 102: 133-138.

Zettler LW, Perlman S, Dennis DJ, Hopkins SE, Poulter SB (2005a) Symbiotic germination of the Federally endangered Hawaiian endemic, Platanthera holochila (Orchidaceae) using a mycobiont from Florida: a conservation dilemma. Selbyana 26(1,2): 269-276.
Zettler LW, Piskin KA, Stewart SL, Hartsock JJ, Bowles ML, Bell TJ (2005b) Protocorm mycobionts of a Federally threatened orchid, Platanthera leucophaea, and a technique to promote leaf formation in seedlings. Stud Mycol 53: 163-171.

\section{Appendix 1}

Protocol summary for cultivating Platanthera holochila from seed on asymbiotic media

1. Mature seeds should be acquired from yellowing capsules just prior to dehiscence.

2. Capsules should be promptly ( $<48 \mathrm{hrs}$ ) dried over desiccant (e.g., Drierite, $\mathrm{CaSO}_{4}$ ) for ca. 1 week at ambient temperature until seeds are thoroughly dry. Prior to drying, capsules should be temporarily stored in a container that allows for some gas exchange yet minimizes moisture build-up to discourage mold growth.

3. Using a sterile scalpel and forceps, dry seeds should be gently removed from capsules, placed into a sterile glass vial, and tightly sealed. Seeds can then be immediately frozen $\left(-7^{\circ} \mathrm{C}\right)$ in a viable state for at least 5 years in cold storage. Seeds can also be sown directly onto agar after drying circumventing cold storage. Cold moist stratification treatment is unnecessary as seed dormancy mechanisms are apparently lacking in this species.

4. Prior to sowing on agar, seeds should be surface sterilized for $1 \mathrm{~min}$ in a solution of 5\% absolute $\mathrm{EtOH}, 5 \%$ Clorox ${ }^{8}$ bleach $(5.25 \% \mathrm{NaOCl})$ and $90 \%$ sterile DI water, followed by two sterile DI water rinses each lasting $1 \mathrm{~min}$. Seeds apparently can withstand higher bleach concentrations (e.g., 10\%) without appreciable drop in embryo viability.

5. Using a sterile wire inoculation loop, clumps of seeds are removed from the 2 nd DI water rinse and added to the surface of P723 (PhytoTechnology Labs) within 9 $\mathrm{cm}$ diam. sterile Petri plates. The $\mathrm{pH}$ of the agar should be lowered to 5.0 prior to autoclaving with HCI.

6. Each plate should be wrapped with a strip of Parafilm " $\mathrm{M}$ " to retain internal moisture levels while excluding potential contaminants. Plates are then wrapped tightly with aluminum foil to exclude light and incubated at $16-19^{\circ} \mathrm{C}$ for ca. 450 days.

7. Colorless (white) leaf-bearing seedlings should be exposed to illumination $>450$ days by permanently removing aluminum foil. Irradiance, provided by fullspectrum bulbs (e.g., Sylvania $\mathrm{Hg} / 32 \mathrm{~W}$ Octron $410 \mathrm{OK}$, F032/841/ECO) should measure ca. $80 \mu \mathrm{mol} \mathrm{m}^{2} 2^{-1}$, with a photoperiod cycle of $12 \mathrm{hrs}$ light : $12 \mathrm{hrs}$ darkness. Every attempt should be made to exclude light during the dark cycle without interruption. Seedlings should be incubated under these conditions for at least 200 days within their original plates.

8. After 200 days under illumination, leaf-bearing seedlings should be transferred to fresh (acidified) P723 
within raised culture vessels. The lid of each vessel should be wrapped with Parafilm "M", vessels and seedlings promptly returned to experimental conditions for another 12 months.

9. Seedlings of sufficient size (e.g., basal leaf $>2 \mathrm{~cm}$ in length) can be deflasked (ex vitro), placed in pots containing pre-sterilized carnivorous plant mix (CP), ground tree fern (TF; Tree Fern Fiber Long, OFE International Inc.), and builder's sand (BS; Quikrete All-Purpose Sand, No. 1152, Quikrete International
Inc.) in a ratio of $4: 2: 1$ (CP:TF:BS), and exposed to natural illumination (e.g., greenhouse conditions) for 2-6 months. During this time, temperatures should remain $\operatorname{cool}\left(5{ }^{\circ} \mathrm{C}\right.$ minimum $/ 22^{\circ} \mathrm{C}$ maximum), and not exceed $25^{\circ} \mathrm{C}$. Potting mix must remain constantly moist. 10. Greenhouse established seedlings should be reintroduced into suitable habitats at higher elevations $(600-1500 \mathrm{~m})$ at the onset of Hawaii's growing season (e.g., February-April). Seedlings should receive no more than 6-8 hrs of direct sunlight. 